This is an electronic reprint of the original article. This reprint may differ from the original in pagination and typographic detail.

Author(s): Wang, Qingju; Chen, Decai; Cheng, Shumei; Nicholson, Patrick; Alen, Markku; Cheng, Sulin

Title: Growth and aging of proximal femoral bone - a study with women spanning three generations

Year: $\quad 2015$

Version:

Please cite the original version:

Wang, Q., Chen, D., Cheng, S., Nicholson, P., Alen, M., \& Cheng, S. (2015). Growth and aging of proximal femoral bone - a study with women spanning three generations. Journal of bone and mineral research, 30(3), 424-430.

https://doi.org/10.1002/jbmr.2353

All material supplied via JYX is protected by copyright and other intellectual property rights, and duplication or sale of all or part of any of the repository collections is not permitted, except that material may be duplicated by you for your research use or educational purposes in electronic or print form. You must obtain permission for any other use. Electronic or print copies may not be offered, whether for sale or otherwise to anyone who is not an authorised user. 


\section{Growth and aging of proximal femoral bone - a study with women spanning three generations ${ }^{\dagger}$}

Qin Wang ${ }^{1,2}$, Decai Chen ${ }^{1}$, Shu Mei Che ${ }^{2}{ }^{2}$, Patrick Nicholson ${ }^{2}$, Markku Alen ${ }^{3}$, Sulin Cheng ${ }^{4,2}$

${ }^{1}$ Department of Endocrinology, West China Hospital of Sichuan University, Sichuan, China; ${ }^{2}$ Department of Health Sciences, University of Jyväskylä, Jyväskylä, Finland;

${ }^{3}$ Department of Medical Rehabilitation, Oulu University Hospital and Institute of Health Sciences, University of Oulu, Oulu, Finland;

${ }^{4}$ Department of Sport and Physical Education, Shanghai Jiao Tong University, Shanghai, China

This study was financially supported by the Academy of Finland, Ministry of Education of Finland, University of Jyväskylä and the 2012 China National Science and Technology Infrastructure Program (Grant No. 2012BAK21B03-4). Shanghai Jiao Tong University Zhiyuan Foundation.

Running title: Developmental patterns of proximal femoral bones among three generations

E-mails to authors: dr.qinwang@hotmail.com; 18980601309@163.com; shumeich@hotmail.com patrick_nicholson@btopenworld.com; markku.alen@jyu.fi; shulin.cheng@jyu.fi

Corresponding Author: Prof. Sulin Cheng, Department of Sport and Physical Education, Shanghai Jiao Tong University, Shanghai, 200240, China and Department of Health Sciences, FIN-40014 University of Jyväskylä, Finland.

Tel: +358 142602091 Fax: +358 142602011 E-mail: shulin.cheng@jyu.fi

\section{Competing interests}

The author(s) declare that they have no competing interests.

${ }^{\dagger}$ This article has been accepted for publication and undergone full peer review but has not been through the copyediting, typesetting, pagination and proofreading process, which may lead to differences between this version and the Version of Record. Please cite this article as doi: [10.1002/jbmr.2353] 


\begin{abstract}
Osteoporotic hip fracture is a serious clinical event associated with high morbidity and mortality. Understanding femoral growth patterns is important for promoting bone health in the young and preventing fractures in later life. In this study, growth patterns of areal bone mineral density (aBMD) and geometric properties of the proximal femur were measured by duakenergy X-ray absorptiometry (GE Lunar Prodigy, USA). They were studied in 251 girls from premenarche (11.2 $\pm 0.7 \mathrm{yrs})$ to late adolescence $(18.3 \pm 1.1 \mathrm{yrs})$, and compared to their premenopausal mothers $(\mathrm{n}=128$, aged $44.9 \pm 4.1 \mathrm{yrs})$ and postmenopausal grandmothers $(\mathrm{n}=128$, aged $70.0 \pm 6.3 \mathrm{yrs})$. Hip axis length (HAL) was the first to reach peak growth velocity (-10.5 months prior to menarche), followed by neck diameter (ND) and neck cross-sectional area (CSA), (-7.1 and -4.1 months prior to menarche, respectively). Both neck-shaft angle (NSA) and aBMD of neck and total hip peaked at menarche. At 18 yrs (7-yr follow-up), girls already had higher femoral neck aBMD but similar HAL and NSA compared with their mothers. Grandmothers had the longest HAL, narrowest NSA, widest ND but lowest aBMD and CSA. Hip Strength Index (HSI), an index of femoral neck strength during a fall, dropped rapidly after menarche in girls but thereafter remained relatively constant. Grandmothers had lower HSI than either mothers or girls. In conclusion, differences in proximal femoral bone mass and structure in adulthood are largely established prior to menarche, indicating that heritable factors are responsible for most of the individual variance. The development of geometric properties precedes aBMD in puberty, resulting in relatively constant hip strength after menarche. This asynchronous growth leads to adaption of bone strength to the imposed loads, avoiding fractures in a biologically efficient manner. Both deterioration of aBMD and inadequate compensatory change in bone geometry after menopause contribute to the increased fracture risk later in life.
\end{abstract}

Key words: puberty, women, hip, bone strength, geometry, and density 


\section{Introduction}

Osteoporosis is the most common metabolic bone disease and is associated with increased risk of fractures (1). The most common fractures are those of the vertebrae (spine), proximal femur (hip) and distal forearm (wrist). Hip fractures account for a 8.4 to $36 \%$ of the total fractures, are associated with considerable excess mortality within one year, and approximately $20 \%$ of hip fracture patients require long-term nursing home care (2). Annually, 3-4 million osteoporotic fractures occur in Europe resulting in direct costs to the health care services of around 30 billion euros (3). In the US osteoporosis-related fractures resulted in a cost of $\$ 17$ billion in 2005, and hip fractures accounted for $14 \%$ of incident fractures and $72 \%$ of fracture costs (4).

It is widely accepted that optimizing bone strength during growth is important to prevent osteoporosis and related fractures later in life (5). Strength of a bone is determined by both its material and structural properties (e.g., bone geometry) (6). Thus determining geometric measures could be helpful to estimate bone strength. There are a number of reports suggesting that bone geometry plays a key role in hip fracture (6-11). Animal studies show that femoral neck width is a positive predictor for femoral neck strength (12-14). Longer hip axis length is related to higher hip fracture risk, especially the sub-head type $(15,16)$.

During growth, optimal bone strength is better achieved by modifying the distribution of bone mass rather than increasing bone mass alone (17). Hence having more optimal bone geometry is an effective way to reduce the risk of osteoporotic fracture later in life. Cross-sectional studies have demonstrated that the natural age-related decline in cross-sectional area (CSA) and cortical thickness at the proximal femur starts around 20 years of age (18). Another study observed an agerelated decline in areal bone mineral density (aBMD) and section modulus $(\mathrm{Z})$ at the proximal femur from 20- to 80-yrs (19). Differences in the BMD of femoral neck in adulthood are largely established before puberty (20), suggesting that the puberty is a critical period for bone growth. However, there are no such longitudinal data from childhood through to old age to confirm whether or not bone traits established in childhood persist to middle age and old age.

In this study, we conducted a 7-yr longitudinal study of the growth patterns of proximal femoral bone traits in a cohort of 251 girls from premenarche (Tanner Stage $1 \& 2$ ) to late adolescence. In addition, these bone traits were also measured in the girls' biological mothers and grandmothers. By 
comparing the data among these three generations it was possible to infer the patterns of change in proximal femur traits from premenarche to postmenopause. Also we assessed the peak velocity time (PVT, the age at which the growth velocity of the selected variable reached a maximum) of aBMD at the femoral neck and total hip, hip axis length (HAL), neck shaft angle (NSA), cross-sectional area of neck (CSA), cross-sectional moment of inertia (CSMI) of neck, and hip strength index (HSI) from DXA scans. Determining PVT is useful in terms of understanding growth trajectories and temporal relationships between different bone properties, and to specify the time point to start intervention for optimization of bone strength during puberty. A family-based study design like that used here may be the best alternative to unfeasible, ultra-long-term longitudinal studies.

\section{Subjects and Methods}

\section{Subjects}

The study population of this report is a part of the CALEX family study that has been described elsewhere (21-23). Briefly, 396 Caucasian girls recruited in the city of Jyväskylä and its surroundings in Central Finland participated in the laboratory tests 1-8 times over a maximum period of 8 years (from 2000 to 2008, mean duration of total follow-up was 7.5 years). Of 396 eligible girls, 258 girls had bone assessments at baseline (mean age $11.2 \mathrm{yrs}$ ), 200 at 12 months, 221 at 24 months, 87 at 42 months and 235 at 84 months. In addition, 257 biological mothers and 154 grandmothers of these girls were invited to participate in one-time bone measurements. Postmenopausal mothers ( $n=129)$, premenopausal grandmothers $(n=26)$, and those who at the time of recruitment had diseases or medication known to affect bone metabolism were excluded. We had to exclude seven 11-yr girls, one 18-yr old girl because of having diseases or taking medicine that affected bone metabolism or unqualified bone image. Finally, 25111 -yr girls (mean age $11.2 \pm 0.7$ yrs), 18912 -yr girls (mean age $12.2 \pm 0.7 \mathrm{yrs}), 21013$-yr girls (mean age $13.2 \pm 0.7 \mathrm{yrs}$ ), 7414 -yr girls (mean age $14.4 \pm 0.9$ yrs), 224 18-yr girls (mean age $18.3 \pm 1.1$ yrs), 128 premenopausal mothers (mean age $44.9 \pm 4.1 \mathrm{yrs}$ ), and 128 postmenopausal grandmothers (mean age $70.0 \pm 6.3 \mathrm{yrs}$ ), were included.

The study protocol was approved both by the ethical committee of the University of Jyväskylä and the Central Finland Health Care District. All the participants and their legal guardians (for minors) 
provided written informed consent (volunteers without monetary compensation) in accordance with the ethical committees of the Central Finland Health Care District.

Measurements

\section{Anthropometry}

Height and weight were obtained by duplicate measurements with subjects wearing light clothes and on bare feet. Height was determined using a fixed wall-scale measuring device to the nearest $0.1 \mathrm{~cm}$. Weight was determined within $0.1 \mathrm{~kg}$ for each subject using an electronic scale and was calibrated before each measurement session. The mean of the two measures was used as the final results. The age of menarche was defined as the first onset of menstrual bleeding and this information was solicited, by questionnaire, retrospective phone call, and/or interview during a clinical visit. We use the term "premenarche" to mean "before menarche".

\section{Bone measures}

Bone measures of the left hip were assessed using dual-energy X-ray absorptiometry (DXA, GE Lunar Prodigy Advance, Madison, WI, USA; software enCORE version 13). The Advanced Hip Assessment (AHA) included in this software calc ulates bone geometry and bone tissue distribution within the femoral neck from a planar scan. The femur ROI is placed automatically in the proximal part of the femoral neck. However, we made a manual adjustment if an obvious error in ROI position was observed. One technician performed data acquisition and analysis. Quality Assurance (QA) test was performed following the instructions of enCORE Operator's Manual each morning before measurement. If manual adjustment of the ROI was needed, a repeated scan was performed and the new scan was used as final result. Left femur was scanned unless the left side is not appropriate due to hardware or fracture. The hip axis length $(\mathrm{HAL}, \mathrm{cm})$ was evaluated as the linear distance from the pelvic rim to the lateral edge of the femur below the greater trochanter and along the femoral neck axis. Neck diameter $(\mathrm{ND}, \mathrm{cm})$ was the average diameter in the ROI. Femoral neck-shaft angle (NSA, degree) was the angle of the intersection of the neck and shaft axes. The software iteratively assessed all cross-sections in the femoral neck region of interest and identified the plane with the minimum cross-sectional moment of inertia $\left(\mathrm{CSMI}, \mathrm{cm}^{4}\right)$, which is a measure of 
bone's resistance to bending forces. The method was developed by Yoshikawa and colleagues (24). A strong linear association between the CSMI measured directly and using DXA has been reported in cadaveric bones $\left(\mathrm{r}^{2}=0.96\right)$. The cross-sectional area $\left(\mathrm{CSA}\right.$, without bone marrow, $\left.\mathrm{cm}^{2}\right)$ was measured in the plane of where CSMI was obtained. Hip Strength Index (HSI) is an index of the strength of the femoral neck during a fall, taking age, weight, height and neck geometry into account (24). Higher values of HSI indicate a stronger femoral neck and better ability to sustain the loads experienced during a fall (25). HSI was calculated as following:

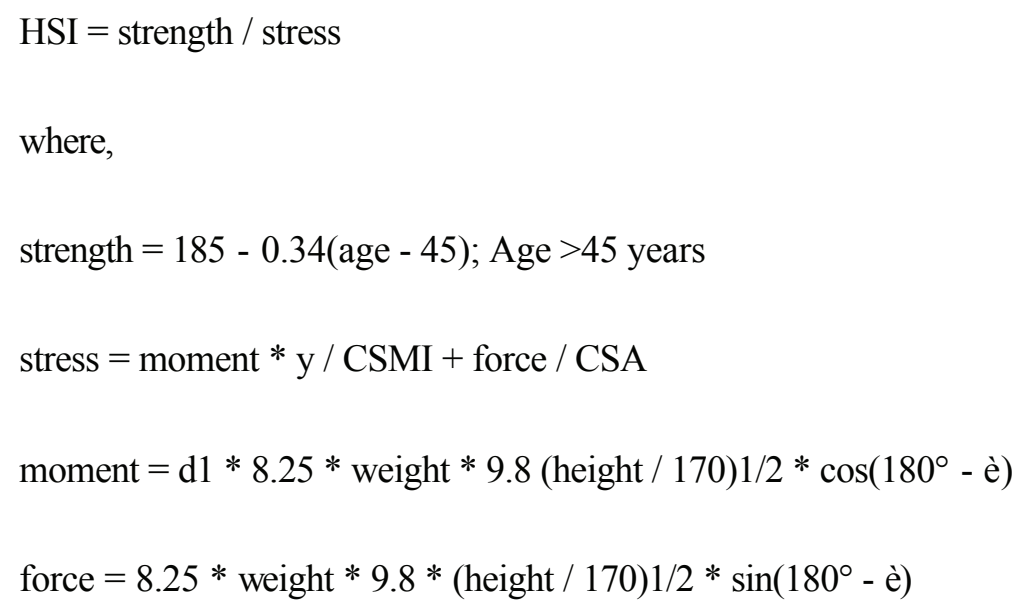

$\mathrm{d} 1=$ Distance along the neck axis from the center of the femoral head to the section of minimum CSMI.

$\mathrm{y}=$ Distance from centre of mass to the upper neck margin, along the section of minimum CSMI.

theta $(\mathrm{e})=$ Angle of the intersection of the neck and shaft axes

The coefficients of variation $(\% \mathrm{CV})$ for aBMD, HAL, NSA, CSA, CSMI and HSI were $0.9 \%$, $2.3 \%, 4.1 \%, 2.6 \%, 1.8 \%$, and $5.2 \%$, respectively. The $\% \mathrm{CV}$ was calculated both in children (22) and adults.

\section{Statistical analysis}

All data were checked for normality before further analysis. If data were not normally distributed, their natural logarithms were used. The descriptive statistical analysis and comparison of three 
generations was done in SPSS 21.0 for WINDOWS (SPSS Inc., Chicago, IL, USA). Analysis of variance (ANOVA) was used to compare differences among different age groups. Given the significant influence of body size on DXA measurements, height was included as the covariate and analysis of covariance (ANCOVA) with the least significant difference (LSD) post-hoc test was used to compare bone parameters. However HSI was not adjusted for height because height is used in the calculation of HSI. The longitudinal analyses of girls' data (from premenarche to late adolescence) were performed using MLwiN 2.02 software (Institute of Education, University of London, London, UK). Hierarchical (multilevel) models with random effects were used to quantify the growth patterns of bone traits. The hierarchical model allows inclusion of the data from every subject regardless of irregularity of temporally spaced follow-up or missing data. Time relative to menarche (TRM), instead of age, was entered as the explanatory variable in the form of polynomial functions to explain the growth of target variables. Up to fifth-order polynomial functions were used in the models. The best model was determined by three criteria: the largest reduction in the deviance $(-2 * \log$-likelihood ratio of the reduced model compared to the full model), the lowest within-individual variance, and the necessary parsimony of the model. The PVT was determined from the maximum in the growth velocity curve. Time of plateauing was determined as the time at which the growth velocity decreased to 0 . A $P<0.05$ was considered statistically significant.

\section{Results}

The growth patterns of aBMD, HAL, NSA, ND, CSA, CSMI and HSI at the femoral neck and total proximal femur in girls from premenarche to late adolescence are shown in Figure 1. All these parameters increased markedly before or around menarche except for NSA and HSI. The neckshaft angle shifted decreased then plateaued around 36 months after menarche. Hip strength index decreased until menarche and then maintained a relative constant value throughout puberty. The Hip axis length, total aBMD, neck aBMD and CSA growth accelerated early and reached a plateau around 20, 49, 57 and 62 months after menarche, respectively. Neck diameter and CSMI curve showed a slow but steady increase after rapid growth around menarche. 
Among all proximal femur bone material and geometric traits, HAL was the first to reach the peak velocity (10.5 months prior to menarche), followed by ND and CSA, (7.1 and 4.1 months prior to menarche, respectively). Both NSA and aBMD of the neck and total hip peaked at menarche (Figure 2). The peak velocity (per month) of HAL, neck diameter, total aBMD, neck aBMD and CSA were $0.44 \mathrm{~cm}, 0.11 \mathrm{~mm}, 6 \mathrm{mg} / \mathrm{cm}^{2}, 0.6 \mathrm{mg} / \mathrm{cm}^{2}$, and $1.19 \mathrm{~mm}^{2}$, respectively.

To evaluate how bone traits at the hip compared across different periods of women's life, we compared these traits among premenarcheal and late adolescence girls to their pre-menopausal mothers and postmenopausal grandmothers. For girls at 11 years of age, all of their proximal femoral bone traits were lower than those of girls at the age 18 yrs except for the NSA, which decreased with age. At the age of 18 yrs (7-yr follow-up), girls already had a higher aBMD at femoral neck than their mothers, whereas aBMD at total hip, HAL, NSA and HSI were similar. However, the $\mathrm{ND}, \mathrm{CSA}$ and CSMI of the femoral neck were still significantly lower in 18 year-old girls than their premenopausal mothers (all were $\mathrm{p}<0.05$ ) (Table 1 ). Compared to 18 -yr girls and their mothers, grandmothers had lower aBMD, CSA and HSI, but higher ND (Table 1 and Figure 1). After adjusted for height, the significant differences of aBMD, ND, CSA and CSMI remained. While NSA was smaller in grandmothers and mothers, compared with 18 -yr girls. Grandmothers had the longest HAL, narrowest NSA, but lowest aBMD and CSA.

\section{Discussion}

In this 7-yr longitudinal follow-up study from premenarche to late adolescence in girls, we found that the growth velocities of geometric parameters of the proximal femur, such as CSA, CSMI of femoral neck, hip axis length and neck diameter, peaked earlier than aBMD. However, the Hip strength index (reflecting the strength of the femoral neck relative to the loads imposed during a fall) remained relatively constant after menarche. These two observations together suggest an asynchronous but well-coordinated growth pattern of the bone adapting to stress during puberty. After puberty, using the data from the three generations to infer lifelong trends, our data indicate that bone density and most of the geometric parameters as well as hip strength index are maintained from late adolescence until menopause but decline thereafter. 


\section{Peak velocity time}

Our previous study looking at the tibia demonstrated that growth velocities of length and CSA peak earlier than that of aBMD (23). Similarly, other researchers have observed such phenomenon in the forearm (26-29). The rapid growth in bone dimensions without a concomitant increase in bone mineral density may contribute to lower mineralization of bone tissue, which is considered to be one of the reasons underlying the elevated risk of forearm fracture during the pubertal growth spurt (3032). Evidence for such a "mineralization deficit" $(33,34)$ was also found in this current study at the proximal femur: the PVT of hip axis length and CSA of femoral neck preceded that of aBMD, indicating that the hip bone mass accrual lags behind the increase in bone size. However, there are no reports of increased hip fracture risk during the pubertal growth spurt. This may be explained by the fact that the proximal femur is much stronger, both in absolute terms and relative to the applied loads, compared to the radius and ulna (35). In addition, the hip is surrounded by more soft tissue than the forearm and this may further reduce the risk of fracture in a fall (32).

\section{Development patterns of proximal femoral bones in three generations}

The fracture risk is closely related to the decrease of aBMD, which has been the most widely studied among all bone traits. In our study, we found that aBMD at the femoral neck and total hip peaked around 18-yrs of age while grandmothers had the lowest aBMD because of the rapid bone loss after menopause as described in many earlier studies $(36,37)$. The CSA of the femoral neck, excluding the bone marrow cavity, was maintained until mid-age. Grandmothers had much smaller CSA than their daughters and their 18-yr granddaughters, despite the fact that their femoral neck diameter was the widest. This apparent paradox may be explained by the growth difference of periosteal diameter (PD) and endosteal diameter (ED), which were unfortunately not measured in this current study. Gayani Alwis and colleagues scanned 1,760 population-based Caucasians aged 6-90 yrs using DXA and analysed by hip structural analysis (HSA)(38). They found that PD and ED of the femoral neck both increased with age, but that ED increased more than PD. Duan and his colleagues also observed that less age-related periosteal than endocortical widening produced cortical thinning in 
femoral neck, increasing the risk for structural failure in both sexes(39). Thus the change of geometry of femoral neck contributed to femoral fragility in old age.

Fracture occurs only when stresses imposed upon a bone exceed the bone strength. CSMI, a geometrical measure of a bones' resistance to bending forces, can be considered as an index of bone strength. According to our three-generation data, the grandmothers' CSMI was twice that of 11-yr girls. Furthermore, other trends in geometric parameters in the grandmothers, such as wider neck diameters and narrower neck-shaft angles, tend in the direction of enhanced bone strength. Such observations imply that, in terms of bone size and geometry the grandmothers should have a stronger proximal femur, but we know that older women actually have a much higher fracture risk than younger women. This apparent contradiction can be explained partly with reference to the low HSI in grandmothers. In older women, the stresses imposed on bone in a fall exceed the bone strength. The mechanical advantages associated with, for example, wider femoral neck diameter and reduced neck-shaft angle fail to compensate other factors that act to compromise bone strength, such as microstructural deterioration and decreased aBMD. In addition, the grandmothers were much heavier than their 11 year old granddaughters $(71 \mathrm{~kg}$ vs. $39 \mathrm{~kg}$ ) and hence the loads on the proximal femur, during normal activities and in falls, will be correspondingly greater in the older women. Hence discordance between bone strength and imposed stresses results in significant higher fracture risk in older females. In addition, decrease in CSA of femoral neck (without bone marrow) also indicated a thinner cortical thickness in grandmothers, which could result in structural instability caused by a tendency for structural failure by local buckling $(39,40)$. Moreover, studies using computed tomography instead of DXA suggest that the age-related change of cortical thickness is site-specific in the femoral neck, and this may also play a role in the deterioration of bone strength $(41,42)$.

Hip Strength Index decreased before menarche and maintained a relatively constant level until menopause. This suggests that girls have more than sufficient bone strength before puberty, but this situation rapidly alters, for example with the rapid weight gain of early puberty tending to increase bone loading. After menarche the proximal femur growth adapts itself to the imposed loading in order to maintain certain level of HSI by the asynchronous growth speed of geometric and material 
parameters. This impressive gene-coded control of growth avoids either wasting of energy or fractures.

This study has some limitations. The bone traits of girl-mother-maternal grandmother trios did not perfectly represent the true longitudinal pattern of bone development and ageing in individuals. The data obtained from close relatives may not be the same as that which would be observed for the same subject followed longitudinally. However, the genetic link and the resemblance in living environment among family members may help minimize possible biases, because the variance in bone properties in the population is largely the result of individual differences in genetic makeup, confounded by lifestyle factors $(43,44)$. Another potential limitation arises from the use of DXA measurements. aBMD, assessed by a $2 \mathrm{D}$ imaging technique such as $\mathrm{DXA}$, is an estimate of the average amount of mineral per unit area in a section of bone facing the detector (45-47). Both CSA and CSMI depend of the amount of mineral present in the femoral neck. Thus they consequently are not totally independent of BMD as geometric parameters. Moreover, the hip analysis software could not determine PD and ED, making it difficult to directly explain the change of CSA.

In conclusion, we found that the growth in geometric parameters of proximal femur precedes that of aBMD in puberty. However, the hip strength remained relatively constant after menarche, suggesting an asynchronous but well-coordinated growth pattern of the bone adapting to stress during puberty. This asynchronous growth control leads to a balance of bone strength to stress, avoiding fractures while minimizing wasted energy and resources. Using the data from three generations to indicate lifelong change of the bone traits, we infer that both the deterioration of BMD and the inadequate compensatory changes in bone geometric parameters after menopause contribute to the increased fracture risk later in life. 
Table 1. General Characteristics and DXA Measurements of Finnish Women in Different Age Groups

\begin{tabular}{|c|c|c|c|c|}
\hline & 11-yr girls & 18-yr girls & Mothers & Grandmothers \\
\hline $\mathrm{N}$ & 251 & 224 & 128 & 128 \\
\hline Age (yr) & $11.2 \pm 0.7$ & $18.3 \pm 1.1^{*}$ & $44.9 \pm 4.1^{\dagger \dagger}$ & $70.0 \pm 6.3^{\#}$ \\
\hline Height (cm) & $145.7 \pm 8.1$ & $165.8 \pm 5.7^{*}$ & $165.5 \pm 5.6^{*}$ & $159.8 \pm 4.9^{\#}$ \\
\hline Weight $(\mathrm{kg})$ & $39.0 \pm 8.4$ & $60.0 \pm 9.7^{*}$ & $70.0 \pm 13.8^{\dagger \dagger}$ & $71.0 \pm 11.0^{\#}$ \\
\hline BMI $\left(\mathrm{kg} / \mathrm{m}^{2}\right)$ & $18.2 \pm 2.8$ & $19.8 \pm 3.5^{*}$ & $25.5 \pm 4.6^{\dagger+}$ & $28.4 \pm 8.4^{\#}$ \\
\hline Neck aBMD $\left(\mathrm{g} / \mathrm{cm}^{2}\right)$ & $0.82 \pm 0.09$ & $1.06 \pm 0.14^{*}$ & $1.00 \pm 0.12^{\dagger *}$ & $0.86 \pm 0.14^{\#}$ \\
\hline Total hip aBMD $\left(\mathrm{g} / \mathrm{cm}^{2}\right)$ & $0.83 \pm 0.10$ & $1.08 \pm 0.13 *$ & $1.06 \pm 0.12^{*}$ & $0.94 \pm 0.14^{\#}$ \\
\hline $\mathrm{HAL}(\mathrm{mm})$ & $93.5 \pm 6.7$ & $102.8 \pm 5.7 *$ & $103.9 \pm 5.8^{\ddagger}$ & $104.3 \pm 5.7^{\#}$ \\
\hline $\operatorname{NSA}\left({ }^{\circ}\right)$ & $130.5 \pm 4.0$ & $127.1 \pm 3.5^{*}$ & $126.4 \pm 3.4$ & $125.3 \pm 4.5^{\#}$ \\
\hline $\mathrm{ND}(\mathrm{mm})$ & $26.7 \pm 2.3$ & $30.6 \pm 2.1^{*}$ & $32.2 \pm 2.0^{\dagger \dagger}$ & $33.0 \pm 2.2^{\#}$ \\
\hline $\mathrm{CSA}\left(\mathrm{mm}^{2}\right)$ & $101.1 \pm 15.8$ & $151.7 \pm 22.1 *$ & $152.5 \pm 20.6^{\ddagger}$ & $131.5 \pm 22.6^{\#}$ \\
\hline $\operatorname{CSMI}\left(\mathrm{mm}^{4}\right)$ & $4671 \pm 1431$ & $9086 \pm 2132 *$ & $10204 \pm 2157^{\dagger+}$ & $9537 \pm 2247^{\#}$ \\
\hline HSI & $1.89 \pm 0.45$ & $1.78 \pm 0.35^{*}$ & $1.75 \pm 0.36^{\ddagger}$ & $1.57 \pm 0.42^{\#}$ \\
\hline
\end{tabular}

Data was shown as mean \pm standard deviation. $\mathrm{aBMD}=$ areal bone mineral density, $\mathrm{HAL}=$ hip axis length, $\mathrm{NSA}=$ neck-shaft angle, $\mathrm{ND}=$ Neck diameter, $\mathrm{CSA}=$ cross- sectional area, $\mathrm{CSMI}=$ crosssectional moment of inertia, HSI=hip strength index. Bone parameters were adjusted for height except HSI.

*: 11 -yr girls vs. 18-yr girls $\mathrm{p} \varangle 0.001$

${ }^{\dagger}$ : Mothers vs. 18-yr girls $\mathrm{p}<0.001$

\$: Mothers vs. Grandmothers $\mathrm{p}<0.05$

\#. Grandmothers vs. 18-yr girls $\mathrm{p}<0.05$ 
Figure Legends:

Figure 1. Growth patterns of femoral neck and total hip aBMD, HAL, NSA, ND, CSA, CSMI and HSI. Data for the bone traits are plotted against time relative to menarche (TRM). Gray lines represent longitudinal change of each individual's values and the black lines are the best fitting lines derived from hierarchical models. Mothers' and grandmothers' values are indicated by box with error bars (mean and 95\% CI). Label "M" means mothers and "GM" means grandmothers. aBMD=areal bone mineral density, HAL=hip axis length, NSA=neck-shaft angle, CSA=cross-sectional area, $\mathrm{CSMI}=$ cross- sectional moment of inertia, HSI=hip strength index.

Figure 2. Peak velocity time of proximal femoral material and structural traits. aBMD=bone mineral density, $\mathrm{HAL}=$ hip axis length, $\mathrm{NSA}=$ neck-shaft angle, $\mathrm{CSA}=$ cross-sectional area. 
1. 2004 Bone Health and Osteoporosis: A Report of the Surgeon General, Rockville (MD).

2. Abrahamsen BVS, T;Ariely, R; Olson, M; Cooper,C 2009 Excess mortality following hip fracture: a systematic epidemiological review. Osteoporos Int 20(10):879-883.

3. Alzahouri K, Bahrami S, Durand-Zaleski I, Guillemin F, Roux C 2013 Costeffectiveness of osteoporosis treatments in postmenopausal women using FRAX thresholds for decision. Joint Bone Spine 80(1):64-9.

4. Burge RTD-H, B; Solomon,D; Wong, JB; King AB; Tosteson, ANA. 2007 Incidence and economic burden of osteoporotic fractures in the United States, 2005-2025. J Bone Min Res 22(3):465-475.

5. Heaney RP, Abrams S, Dawson-Hughes B, Looker A, Marcus R, Matkovic V, Weaver C 2000 Peak bone mass. Osteoporos Int 11(12):985-1009.

6. Gregory JS, Aspden, R.M. 2008 Femoral geometry as a risk factor for osteoporotic hip fracture in men and women. Medical Engineering \& Physics 30: $1275-1286$.

7. Baker-Lepain JC, Luker KR, Lynch JA, Parimi N, Nevitt MC, Lane NE 2010 Active shape modeling of the hip in prediction of incident hip fracture. J Bone Miner Res.

8. Crabtree NJ, Kroger H, Martin A, Pols HA, Lorenc R, Nijs J, Stepan JJ, Falch JA, Miazgowski T, Grazio S, Raptou P, Adams J, Collings A, Khaw KT, Rushton N, Lunt M, Dixon AK, Reeve J 2002 Improving risk assessment: hip geometry, bone mineral distribution and bone strength in hip fracture cases and controls. The EPOS study. European Prospective Osteoporosis Study. Osteoporos Int 13(1):48-54.

9. Haapasalo H, Kontulainen S, Sievanen H, Kannus P, Jarvinen M, Vuori I 2000 Exercise-induced bone gain is due to enlargement in bone size without a change in volumetric bone density: a peripheral quantitative computed tomography study of the upper arms of male tennis players. Bone 27(3):351-7.

10. Heaney RP, Barger-Lux MJ, Davies KM, Ryan RA, Johnson ML, Gong G 1997 Bone dimensional change with age: interactions of genetic, hormonal, and body size variables. Osteoporos Int 7(5):426-31.

11. Humphry 1889 The Angle of the Neck with the Shaft of the Femur at Different Periods of Life and under Different Circumstances. J Anat Physiol 23(Pt 2):273-82.

12. Bonnaire FA, Buitrago-Tellez C, Schmal H, Gotze B, Weber AT 2002 Correlation of bone density and geometric parameters to the mechanical strength of the femoral neck. Injury 33 Suppl 3:C47-53.

13. Cheng XG, Yang DZ, Zhou Q, Zhuo TJ, Zhang HC, Xiang J, Wang HF, Ou PZ, Liu JL, Xu L, Huang GY, Huang QR, Barden HS, Weynand LS, Faulkner KG, Meng XW 2007 Age-related bone mineral density, bone loss rate, prevalence of osteoporosis, and reference database of women at multiple centers in China. J Clin Densitom 10(3):276-84. 
14. Kukla C, Gaebler C, Pichl RW, Prokesch R, Heinze G, Heinz T 2002 Predictive geometric factors in a standardized model of femoral neck fracture. Experimental study of cadaveric human femurs. Injury 33(5):427-33.

15. Duboeuf F, Hans D, Schott AM, Kotzki PO, Favier F, Marcelli C, Meunier PJ, Delmas PD 1997 Different morphometric and densitometric parameters predict cervical and trochanteric hip fracture: the EPIDOS Study. J Bone Miner Res 12(11):1895-902.

16. Gnudi S, Ripamonti C, Lisi L, Fini M, Giardino R, Giavaresi G 2002 Proximal femur geometry to detect and distinguish femoral neck fractures from trochanteric fractures in postmenopausal women. Osteoporos Int 13(1):69-73.

17. Seeman E 2008 Structural basis of growth-related gain and age-related loss of bone strength. Rheumatology (Oxford) 47 Suppl 4:iv2-8.

18. Zhang F, Tan LJ, Lei SF, Deng HW 2010 The differences of femoral neck geometric parameters: effects of age, gender and race. Osteoporos Int 21(7):120514.

19. Beck TJ, Ruff CB, Bissessur K 1993 Age-related changes in female femoral neck geometry: implications for bone strength. Calcif Tissue Int 53 Suppl 1:S41-6.

20. Buttazzoni C, Rosengren BE, Tveit M, Landin L, Nilsson JA, Karlsson MK 2014 A pediatric bone mass scan has poor ability to predict adult bone mass: a 28-year prospective study in 214 children. Calcif Tissue Int 94(2):232-9.

21. Cheng S, Lyytikainen A, Kroger H, Lamberg-Allardt C, Alen M, Koistinen A, Wang QJ, Suuriniemi M, Suominen H, Mahonen A, Nicholson PH, Ivaska KK, Korpela R, Ohlsson C, Vaananen KH, Tylavsky F 2005 Effects of calcium, dairy product, and vitamin $\mathrm{D}$ supplementation on bone mass accrual and body composition in 10-12-y-old girls: a 2-y randomized trial. Am J Clin Nutr 82(5):1115-26; quiz 1147-8.

22. Cheng S, Volgyi E, Tylavsky FA, Lyytikainen A, Tormakangas T, Xu L, Cheng SM, Kroger H, Alen M, Kujala UM 2009 Trait-specific tracking and determinants of body composition: a 7-year follow-up study of pubertal growth in girls. BMC Med 7:5.

23. $\mathrm{Xu} \mathrm{L}$, Nicholson P, Wang Q, Alen M, Cheng S 2009 Bone and muscle development during puberty in girls: a seven-year longitudinal study. J Bone Miner Res 24(10):1693-8.

24. Yoshikawa T, Turner CH, Peacock M, Slemenda CW, Weaver CM, Teegarden D, Markwardt P, Burr DB 1994 Geometric structure of the femoral neck measured using duat energy x-ray absorptiometry. J Bone Miner Res 9(7):1053-64.

25. Faulkner KG, Wacker WK, Barden HS, Simonelli C, Burke PK, Ragi S, Del Rio L 2006 Femur strength index predicts hip fracture independent of bone density and hip axis length. Osteoporos Int 17(4):593-9.

26. Bailey DA, Wedge JH, McCulloch RG, Martin AD, Bernhardson SC 1989 Epidemiology of fractures of the distal end of the radius in children as associated with growth. J Bone Joint Surg Am 71(8):1225-31. 
27. Clark EM, Ness AR, Bishop NJ, Tobias JH 2006 Association between bone mass and fractures in children: a prospective cohort study. J Bone Miner Res 21(9):1489-95.

28. Cooper C, Dennison EM, Leufkens HG, Bishop N, van Staa TP 2004 Epidemiology of childhood fractures in Britain: a study using the general practice research database. J Bone Miner Res 19(12):1976-81.

29. Landin LA 1983 Fracture patterns in children. Analysis of 8,682 fractures with special reference to incidence, etiology and secular changes in a Swedish urban population 1950-1979. Acta Orthop Scand Suppl 202:1-109.

30. Kirmani S, Christen D, van Lenthe GH, Fischer PR, Bouxsein ML, McCready LK, Melton LJ, 3rd, Riggs BL, Amin S, Muller R, Khosla S 2009 Bone structure at the distal radius during adolescent growth. J Bone Miner Res 24(6):1033-42.

31. Parfitt AM 1994 The two faces of growth: benefits and risks to bone integrity. Osteoporos Int 4(6):382-98.

32. Wang Q, Alen M, Nicholson P, Lyytikainen A, Suuriniemi M, Helkala E, Suominen H, Cheng S 2005 Growth patterns at distal radius and tibial shaft in pubertal girls: a 2-year longitudinal study. J Bone Miner Res 20(6):954-61.

33. Bass S, Delmas PD, Pearce G, Hendrich E, Tabensky A, Seeman E 1999 The differing tempo of growth in bone size, mass, and density in girls is region-specific. J Clin Invest 104(6): 795-804.

34. Fournier PE, Rizzoli R, Slosman DO, Theintz G, Bonjour JP 1997 Asynchrony between the rates of standing height gain and bone mass accumulation during puberty. Osteoporos Int 7(6):525-32.

35. Dowthwaite JN, Rosenbaum PF, Scerpella TA 2012 Site-specific advantages in skeletal geometry and strength at the proximal femur and forearm in young female gymnasts. Bone 50(5):1173-83.

36. Riggs BL, Melton Iii LJ, 3rd, Robb RA, Camp JJ, Atkinson EJ, Peterson JM, Rouleau PA, McCollough CH, Bouxsein ML, Khosla S 2004 Population-based study of age and sex differences in bone volumetric density, size, geometry, and structure at different skeletal sites. J Bone Miner Res 19(12):1945-54.

37. Riggs BL, Khosla S, Melton LJ, 3rd 2002 Sex steroids and the construction and conservation of the adult skeleton. Endocr Rev 23(3):279-302.

38. Alwis G, Karlsson C, Stenevi-Lundgren S, Rosengren BE, Karlsson MK 2012 Femoral neck bone strength estimated by hip structural analysis (HSA) in Swedish Caucasians aged 6-90 years. Calcif Tissue Int 90(3):174-85.

39. Duan Y, Beck TJ, Wang XF, Seeman E 2003 Structural and biomechanical basis of sexual dimorphism in femoral neck fragility has its origins in growth and aging. $\mathrm{J}$ Bone Miner Res 18(10):1766-74.

40. Beck TJ, Oreskovic TL, Stone KL, Ruff CB, Ensrud K, Nevitt MC, Genant HK, Cummings SR 2001 Structural adaptation to changing skeletal load in the 
progression toward hip fragility: the study of osteoporotic fractures. J Bone Miner Res 16(6):1108-19.

41. Mayhew PM, Thomas CD, Clement JG, Loveridge N, Beck TJ, Bonfield W, Burgoyne CJ, Reeve J 2005 Relation between age, femoral neck cortical stability, and hip fracture risk. Lancet 366(9480): 129-35.

42. Poole KE, Mayhew PM, Rose CM, Brown JK, Bearcroft PJ, Loveridge N, Reeve J 2010 Changing structure of the femoral neck across the adult female lifespan. J Bone Miner Res 25(3):482-91.

43. Pocock NA, Eisman JA, Hopper JL, Yeates MG, Sambrook PN, Eberl S 1987 Genetic determinants of bone mass in adults. A twin study. J Clin Invest 80(3):70610.

44. Smith DM, Nance WE, Kang KW, Christian JC, Johnston CC, Jr. 1973 Genetic factors in determining bone mass. J Clin Invest 52(11):2800-8.

45. Bolotin HH 2001 Inaccuracies inherent in duakenergy X-ray absorptiometry in vivo bone mineral densitometry may flaw osteopenic/osteoporotic interpretations and mislead assessment of antiresorptive therapy effectiveness. Bone 28(5):548-55.

46. Bolotin HH 2007 DXA in vivo BMD methodology: an erroneous and misleading research and clinical gauge of bone mineral status, bone fragility, and bone remodelling. Bone 41(1):138-54.

47. Pickhardt P, Bodeen G, Brett A, Brown JK, Binkley N 2014 Comparison of Femoral Neck BMD Evaluation Obtained Using Lunar DXA and QCT With Asynchronous Calibration From CT Colonography. J Clin Densitom. DOI:10.1016/j.jocd.2014.03.002

Funding source: This study was financially supported by the Academy of Finland, SKIDKID program, project \#135038, by Oulu University Hospital EVO-research grant 2012 and 2013, and by the China National Science and Technology Infrastructure Program 2012 (Grant No. 2012BAK21B03-4). Shanghai Jiao Tong University Zhiyuan Foundation. 

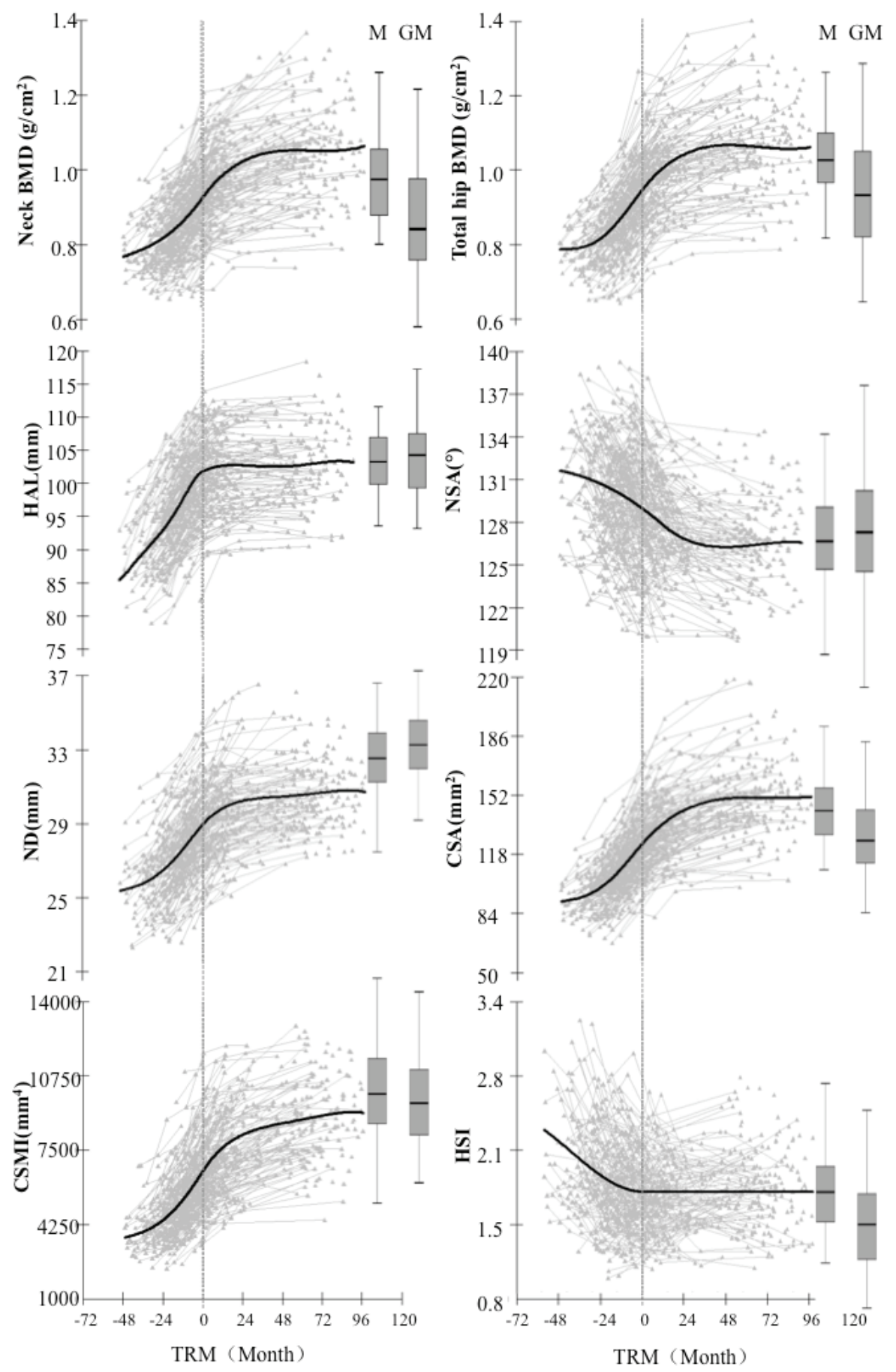

Figure 1 


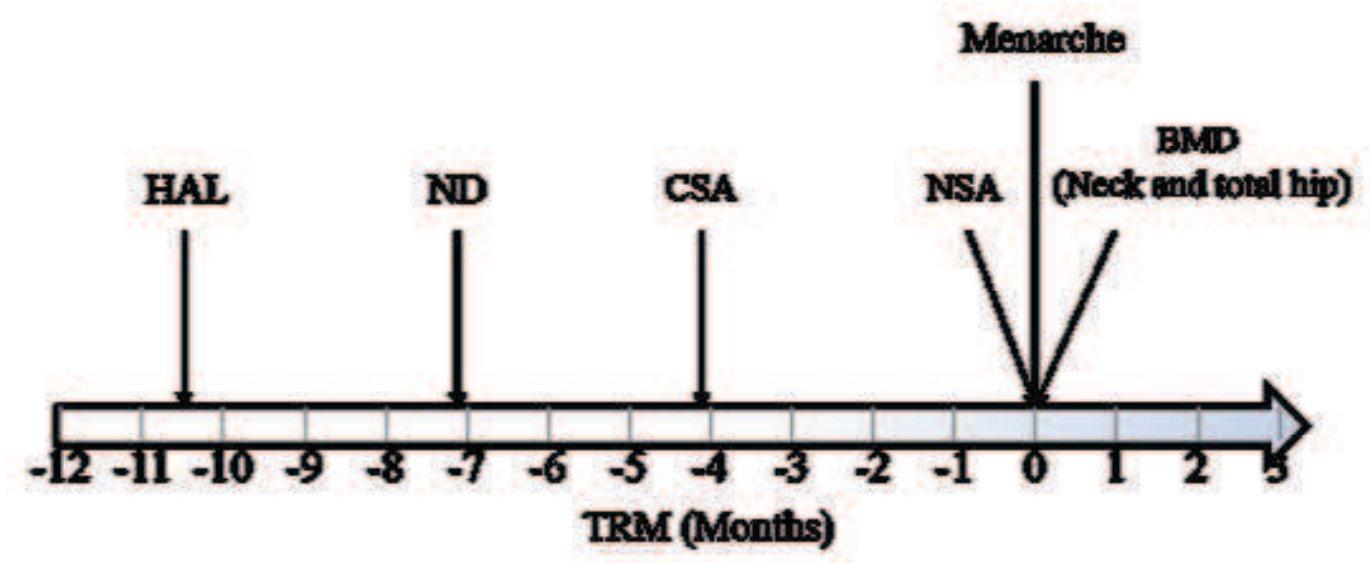

Figure 2 